\title{
Historia y filosofía en la obra de Zea
}

El filósofo mexicano Leopoldo Zea fue uno de los mayores exponentes del pensamiento latinoamericano en el mundo. Buscó incansablemente despertar la conciencia de la latinoamericanidad y el reconocimiento de la región en el concierto global. Su magna obra tuvo como eje y esencia a nuestra América.

El maestro estudió, primero, el ser del mexicano para buscar después la identidad de Hispanoamérica y de la América Latina al incluir al pensamiento brasileño.

El filósofo reivindicó la originalidad del pensamiento latinoamericano frente a quienes niegan el quehacer filosófico de nuestra región; en una filosofía que busca transformar la realidad.

No estoy de acuerdo con [...] que la filosofía sólo puede florecer en 'enclaves de libertad' [...] considero que ha sido la necesidad, el no poseer la plena libertad ni la plena satisfacción de las necesidades materiales y sociales lo que movió al hombre a reflexionar sobre cómo alcanzar lo que tan indispensable le era $[\ldots]$

[...] Aristóteles ya sostenía que la filosofía surge de la necesidad de enfrentar y resolver los problemas que le plantea su circunstancia. [...]

[...] El filósofo piensa para actuar, reflexiona para saber de los problemas $[\ldots]{ }^{1}$

Zea se pronunció por "un filosofar a la altura del hombre, a la altura de sus problemas; no una abstracción”. La filosofía que él cultivó a lo largo de su vida nos legó una obra para enfrentar los retos del tiempo presente.

* Presidenta de la Comisión de Historia del Instituto Panamericano de Geografía e Historia (IPGH).

1 Filosofar a la altura del hombre. Discrepar para comprender, México, UNAM, 1993, 391 pp. 
Pasó de la interpretación histórica a la interpretación filosófica. El filósofo de nuestra América buscó un quehacer filosófico vinculado con la realidad: "la filosofía compromiso". ${ }^{2}$

Zea escribió más de 50 obras y cientos de ensayos, prólogos y artículos de una filosofía comprometida con la posibilidad de transformar la realidad.

En el Pensamiento Latinoamericano, señala:

Si algo define al hombre es la historia; da sentido a lo hecho, a lo que se hace y a lo que se puede seguir haciendo. En la triple dimensión de lo histórico, pasado, presente y futuro, se hace patente el ser del hombre.

Existen hombres, o grupos de hombres que ponen el acento en el pasado, subordinando a él, presente y futuro. Otros, por el contrario, lo ponen en un presente, al que subordinan el pasado y el futuro. Y unos más, lo ponen en un futuro para el cual el pasado y el presente no son sino tramos que es necesario recorrer para su advenimiento. ${ }^{3}$

Historia y filosofía; filosofía e historia, como conjunción inseparable en la obra de Zea, nos lleva a asumir nuestro pasado en forma integradora para comprender nuestro tiempo.

Fue el creador del Seminario sobre Historia de las ideas de América; fundador del Centro Coordinador y Difusor de Estudios Latinoamericanos (CCyDEL). Dirigió hasta su partida el Programa Universitario de Estudios Latinoamericanos y la revista Cuadernos Americanos. Presidió el Comité de Historia de las Ideas del Instituto Panamericano de Geografía e Historia (IPGH) de 1947 a 2004.

Más de una decena de gobiernos y universidades lo condecoraron, cuatro europeos y cuatro latinoamericanos; ocho universidades de seis países de tres continentes.

Recibió el reconocimiento de los gobiernos de Italia, Yugoslavia, Francia y España, de este último obtuvo la Orden Civil de Alfonso X, El Sabio. De América lo reconoció Perú; Venezuela le confirió la orden Andrés Bello y la orden de Libertador en grado de Gran Oficial. Brasil le otorgó el Memorial de América Latina y la orden de Río Branco en grado de Gran Oficial. En el año 2000, México le confirió el máximo reconocimiento que otorga el Senado de la República: la medalla Belisario Domínguez.

2 Palabras del doctor Zea en la entrega del Premio Nacional de Ciencias y Artes, 1980.

3 Zea, Leopoldo, El pensamiento Latinoamericano, México, Editorial Ariel, 3a. ed., 1976, p. 17. 
Recibió en dos ocasiones el Premio Gabriela Mistral, uno de los tres reconocimientos interamericanos de la Organización de Estados Americanos (OEA), para honrar a quienes contribuyen al desarrollo de nuestro continente y proyectan sus valores. Fue seleccionado por unanimidad por haber dedicado la totalidad de su obra a la interpretación de la realidad latinoamericana y a la afirmación de su pensamiento, de entre 37 candidatos de 16 Estados miembros.

$\mathrm{Al}$ otorgarle el reconocimiento al doctor Zea, el Secretario Ejecutivo para la educación, la ciencia y la cultura de la OEA, doctor Enrique Martín del Campo, se refirió al maestro como "la gran figura de México", cuya obra ha contribuido a la identificación y enriquecimiento de la cultura propia de América, así como a la difusión de valores de la cultura universal.

El Secretario General de la OEA, José Clemente Baena Soares hizo un reconocimiento de lo que llamó el "éxito sin precedentes" del doctor Zea en dar a conocer la realidad latinoamericana. Su acción fue reconocida como decisiva en la superación del complejo de inferioridad de las culturas latinoamericanas frente a la europea y a la norteamericana. ${ }^{4}$

En su alocución en la sede de la OEA en Washington, Zea recordó los intentos de unión latinoamericana, el origen de la OEA y la difícil integración entre Estados Unidos y América Latina.

Recorrió los intentos integracionistas latinoamericanos que siguieron los pasos de Bolívar, a Juan Bautista Alberdi, que en 1845 planteó la conveniencia de un Congreso General Americano; al chileno Francisco Bilbao que en 1856 presentó su Iniciativa para un Congreso Federal de Repúblicas; al panameño Justo Arosemena, quien en 1867 planteó un Proyecto de Tratado para fundar una Liga Sudamericana y al nicaragüense Augusto César Sandino, que en 1929 manifestó su Plan para la realización del Supremo Sueño bolivariano; pero ninguno pudo fructificar.

Zea señaló que la "nación de naciones, debe guardar una relación horizontal de solidaridad, no de dominio, para lograr la realización de la libertad”. El reconocimiento de que todos los países son iguales por ser distintos. Una asociación en un plano de igualdad, sin renunciar a la diversidad de identidades. En sus reflexiones destaca la riqueza del mestizaje de razas y

Palabras del embajador Joao Clemente Baena Soares, quien le entregó el Premio Gabriela Mistral, por "su extraordinaria obra de estudioso, difusor e intérprete de la historia de las ideas en América Latina... por su esfuerzo en la promoción de los estudios latinoamericanos y defensa por la dignidad del hombre latinoamericano", Washington, D.C., 25 de noviembre de 1987. 
culturas. Pugnó por la "igualdad en la diferencia", con una fe absoluta en una América multirracial y multicultural.

El maestro Zea fue doctor honoris causa por la Universidad de París, la de Lomonosov de Moscú y la Academia Mexicana de Ciencias de Rusia; por la Universidad de París, Francia; por la Universidad de Montevideo de Uruguay; la Universidad de Cuyo de Argentina; por la Universidad de Santiago de Chile; la Universidad de La Habana en Cuba; y por la Universidad Capodistríaca de Atenas, Grecia, donde fue el primer hispanohablante en recibirlo, reconocido como filheleno y sucesor de José Martí.

En 1999 el IPGH estableció el Premio Pensamiento de América "Leopoldo Zea”, siendo Presidente Noé Pineda Portillo, de Honduras; Secretario General el doctor Carlos A. Carvallo Yáñez, de Chile y Presidente de la Comisión de Historia el doctor Chester Zelaya Goodman, de Costa Rica.

Para seguir el camino trazado por el maestro para difundir el pensamiento de nuestra América, el IPGH otorga el reconocimiento a la trayectoria, Premio Pensamiento de América "Leopoldo Zea". ${ }^{5}$

$5<$ http://comisiones.ipgh.org/HISTORIA/>. 